\title{
Ảnh hưởng của tin tức truyền thông đến dụ̣ báo kiệt quệ tài chính ở các công ty niêm yết tại Việt Nam
}

\section{Influence of financial media reports on financial distress forecasts of listed companies in Vietnam}

\author{
Trần Quang Thành Công ${ }^{1 *}$, Quách Doanh Nghiệp ${ }^{1}$ \\ ${ }^{1}$ Trường Đại học Kinh tế Thành Phố Hồ Chí Minh, Việt Nam \\ *Tác giả liên hệ, Email: tranquangthanhcong@ gmail.com
}

THÔNG TIN

DOI: $10.46223 / \mathrm{HCMCOUJS.}$

econ.vi.13.1.535.2018

Ngày nhận: 19/09/2017

Ngày nhận lại: 14/11/2017

Duyệt đăng: 05/12/2017

Tù khóa:

cường độ phản ánh kiệt quệ của văn bản (Distres Intensity of Default-Corpus DIDC), kiệt quệ tài chính; tin tức từ truyền thông

Keywords:

Distres Intensity Of DefaultCorpus - DIDC, financial distress, media report
TÓM TẮT

Bài nghiên cứu được thực hiện nhằm đánh giá vai trò của tin tức từ các phương tiện truyền thông sẽ ảnh hưởng như thế nào đến việc dự báo tình trạng kiệt quệ tài chính ở các doanh nghiệp niêm yết ở Việt Nam. Chúng tôi đã xây dựng biến DIDC thể hiện "cường độ phản ánh kiệt quệ của văn bản" (distres intensity of default-corpus - DIDC), thông qua khai thác các từ khóa đặc trưng và sự kết hợp các yếu tố tỷ số tài chính, đặc điểm quản trị doanh nghiệp, kinh tế vĩ mô và tin tức truyền thông để xây dựng mô hình dự báo kiệt quệ tài chính. Kết quả chỉ ra rằng các biến thuộc nhóm DIDC có ảnh hưởng cùng chiều đến tình trạng kiệt quệ tài chính, trong đó biến DIDC thuần là biến có ảnh hưởng mạnh mẽ nhất và có hiệu ứng dẫn dắt đối với nhóm biến tin tức truyền thông. Một kết quả khác đó là khi đưa các biến DIDC vào mô hình dự báo kiệt quệ, độ chính xác của mô hình đã tăng lên, điều này chứng minh tin tức truyền thông không chỉ có khả năng giải thích tình hình kiệt quệ tài chính mà còn có thể đưa vào mô hình dự báo kiệt quệ để giúp mô hình trở nên tối ưu hơn.

\section{ABSTRACT}

This paper investigates the impact of financial news from the media on the forecast of financial distress in listed companies in Vietnam. We have built the DIDC variable to show the "distress intensity of default-corpus" (DIDC) by using specific keywords and combining financial factors, corporate governance, macroeconomics and financial media reports to build a default rating model. The results indicate that the DIDC variables have a positive effect on financial distress, in which the pure DIDC is the strongest variable and has the leading effect on the media factors group. The accuracy of the default rating model has 
increased when taking into account DIDC variables. This proves that media reports are not only capable of explaining financial exhaustion but also help the model become more optimal.

\section{Giới thiệu}

Những quyết định cho vay của các tổ chức tài chính thường dựa trên thông tin về rủi ro vỡ nợ của doanh nghiệp. Trên thế giới có nhiều tổ chức xếp hạng doanh nghiệp uy tín như Moody's, Standard and Poor, Fitch. Ở nước ta hiện nay chỉ có một tổ chức xếp hạng tín nhiệm doanh nghiệp là công ty CRV (Credit Rating Vietnam) tuy nhiên chỉ số xếp hạng này vẫn chưa tạo được uy tín và không công bố bảng xếp hạng kể từ 2013. Như vậy vấn đề xếp hạng rủi ro doanh nghiệp ở Việt Nam hiện nay còn khá mới mẻ. Thông thường, các mô hình đánh giá rủi ro của doanh nghiệp thường dựa trên các dữ liệu mang tính chất định lượng được thu thập từ báo cáo tài chính như thông tin về lợi nhuận, các tỷ số tài chính. Mặc dù vậy, trong một số trường hợp, các quyết định đầu tư của nhà đầu tư cá nhân hoặc ngân hàng một phần nào đó dựa trên thông tin có được từ nhiều phương tiện truyền thông khác nhau.

Thời gian qua, với sự bùng nổ về thông tin, công nghệ và mạng xã hội, các tin tức trực tuyến càng thể hiện vai trò và sức ảnh hưởng lớn đối với nhiều lĩnh vực trong đó bao gồm cả lĩnh vực tài chính - ngân hàng. Các trang báo điện tử ngày càng thu hút được lượng truy cập, tìm kiếm thông tin khổng lồ và trở thành một trong những kênh đưa tin quan trọng nhất trong các phương tiện truyền thông đại chúng. Các thông tin chứa đựng từ các báo điện tử này có thể hàm chứa những nội dung rất quan trọng. Tuy nhiên, với đặc thù là một dạng dữ liệu phi cấu trúc, nếu không được xử lý thích hợp, chúng ta sẽ không thể tận dụng được lượng thông tin hữu ích này.

Những năm gần đây, đã có nhiều nhà nghiên cứu trên thế giới sử dụng các kỹ thuật phân tích ngôn ngữ tự nhiên để đưa nội dung từ truyền thông vào các mô hình dự báo kiệt quệ tài chính, vỡ nợ, xếp hạng rủi ro doanh nghiệp. Tại Việt Nam, hầu hết các bài nghiên cứu về kiệt quệ tài chính đều chỉ sử dụng các thông tin mang tính định lượng mà chưa đề cập đến yếu tố thông tin từ truyền thông.

Trong bối cảnh mà các vấn đề như hoạt động yếu kém, kinh doanh thua lỗ, mất khả năng chi trả lãi vay, phá sản, ... của các doanh nghiệp Việt Nam diễn ra ngày càng nhiều thì việc xây dựng một hệ thống dự báo kiệt quệ tài chính, xếp hạng doanh nghiệp hoàn chỉnh kết hợp nhiều yếu tố dự báo trong đó có nội dung từ truyền thông là rất cần thiết, đó là động lực để chúng tôi thực hiện nghiên cứu này.

Nghiên cứu của chúng tôi thực hiện với mục tiêu xây dựng một mô hình dự báo kiệt quệ tài chính dựa trên nhiều yếu tố trong đó có tin tức trực tuyến cho công ty niêm yết trên sàn chứng khoán HOSE và HNX trong khoảng thời gian từ 01/01/2010 đến 31/12/2016.

Điều khác biệt của bài nghiên cứu này so với các bài nghiên cứu trước nằm ở phương pháp ước lượng “cường độ phản ánh kiệt quệ của văn bản”, cách thức xây dựng các từ khóa đặc trưng và sự kết hợp các yếu tố tỷ số tài chính, đặc điểm quản trị doanh nghiệp, kinh tế vĩ mô và tin tức truyền thông để xếp hạng các doanh nghiệp niêm yết trên sàn giao dịch chứng khoán Việt Nam. 


\section{Tổng quan lý thuyết}

\subsection{Anh hưởng của các yếu tố tài chính đến kiệt quệ tài chính}

Beaver (1966) xây dựng mô hình dự báo phá sản đơn biến nhờ sử dụng các biến tài chính, kết quả cho thấy các tỷ số tài chính có khả năng dự báo khá tốt, các tỷ số này có thể dự báo từ 5 năm trước khi kiệt quệ tài chính xảy ra.

Altman (1968) thực hiện một phân tích đa biệt số MDA (multiple discriminant analysis) trên 66 công ty gồm 33 công ty phá sản và 33 công ty không phá sản để lọc ra 5 chỉ số tài chính tốt nhất nhằm xây dựng mô hình dự báo vỡ nợ gồm: vốn luân chuyển trên tổng tài sản, lợi nhuận chưa phân phối trên tổng tài sản, lợi nhuận trước thuế và lãi vay (EBIT) trên tổng tài sản, giá trị thị trường trên tổng nợ, doanh thu trên tài sản. Các tỷ số này được sử dụng để xây dựng một công thức tính nguy cơ phá sản - chỉ số Z - Score.

Altman (2000) đã nghiên cứu và đề xuất một chỉ số mới là ZETA. Cũng như Z - score, chỉ số này cũng được xây dựng từ các biến tỷ số tài chính tuy nhiên có khả năng dự báo kiệt quệ tài chính cao hơn với mức dự báo đúng lên đến $96 \%$ trong năm trước phá sản.

Bhimani, Gulamhussen, và Lopes (2010) cho thấy các chỉ số chi phí lãi vay trên lợi nhuận gộp, khoản phải thu và số ngày phải trả có tác động cùng chiều và đáng kể đến khả năng vỡ nợ của doanh nghiệp. Các biến bảo hiểm tài sản, tỷ lệ đầu tư, thu nhập trên vốn cổ phần và vốn đầu tư, sự khác biệt về lợi nhuận gộp và vốn lưu động trên tổng tài sản có mối quan hệ nghịch chiều đến khả năng vỡ nợ của doanh nghiệp trong mô hình dự báo.

\subsection{Anh hương của các yếu tố vĩ mô đến kiệt quệ tài chính}

Môi trường kinh tế vĩ mô luôn có ảnh hưởng trực tiếp hay gián tiếp đến hoạt động của một doanh nghiệp. Các nghiên cứu của Figlewski, Frydman, và Liang (2006) cho thấy yếu tố kinh tế vĩ mô có tác động đến khả năng thanh toán của nhiều doanh nghiệp. Tinoco và Wilson (2013) đã phát triển mô hình đo lường rủi ro cho các công ty niêm yết để dự đoán kiệt quệ tài chính và phá sản cho thấy ảnh hưởng của các biến số vĩ mô lên xác suất phá sản của doanh nghiệp.

\subsection{Anh hưởng của các yếu tố quản trị công ty đến kiệt quệ tài chính}

Prowse (1998), Rajan và Zingales (1998) đã chỉ ra rằng một dấu hiệu thường thấy của nhiều công ty vỡ nợ tại châu Á là sự tập trung quyền sở hữu quá mức. Johnson, Boone, Breach, và Friedman (2000) cũng xác nhận rằng trong thời gian suy thoái, đã có nhiều vấn đề nghiêm trọng liên quan đến chi phí đại diện ở các quốc gia mà kỹ thuật quản trị doanh nghiệp còn yếu kém.

Lee và Yeh (2004) đã sử dụng ba biến số tỷ lệ nắm giữ bởi cổ đông có quyền kiểm soát, tỷ lệ cầm cố và các quyền lưu chuyển tiền mặt để đại diện cho rủi ro quản trị doanh nghiệp ở Đài Loan. Kết quả nghiên cứu cho thấy rằng ba yếu tố trên ảnh hưởng cùng chiều đến nguy cơ khủng hoảng tài chính trong năm tiếp theo. Nhìn chung, các doanh nghiệp có hệ thống quản trị doanh nghiệp yếu kém dễ bị suy thoái kinh tế và khả năng rơi vào khủng hoảng tài chính. 
Cao, Leng, Feroz, và Davalos (2015) cho thấy rằng quy mô hội đồng quản trị nhỏ, mức độ độc lập của hội đồng quản trị cao, sự đa dạng giới tính trong hội đồng quản trị cao và sự tập trung về quyền lực ở bộ máy quản trị thấp, tất cả đều giúp công ty giảm thiểu rủi ro vỡ nợ.

Như các nghiên cứu ở trên đã đề cập, một doanh nghiệp có các đặc điểm quản trị yếu kém sẽ làm gia tăng các rủi ro đồng thời rất khó để vượt qua các cú sốc trong nền kinh tế. Có rất nhiều đặc điểm quản trị công ty liên quan đến các rủi ro như vấn đề sở hữu, vấn đề quyền lực, vấn đề về giới tính. Do một số công ty, đặc biệt là nhóm công ty kiệt quệ tài chính ở Việt Nam không công bố hoặc công bố không đầy đủ về tỷ lệ sở hữu của hội đồng quản trị hoặc ban giám đốc nên trong nghiên cứu này chúng tôi chỉ chọn 2 biến đại diện cho nhóm biến quản trị công ty là biến $\mathrm{CEO}$ và biến Sở hữu chéo, cả 2 đều là biến giả. Sự tập trung quyền lực và tình trạng sở hữu chéo đều có tác động tiêu cực đến mức độ an toàn của doanh nghiệp. Biến CEO đại diện cho thuộc tính "tập trung quyền lực" nhận giá trị là 1 nếu chủ tịch hội đồng quản trị và giám đốc của công ty là một người và đạt giá trị là 0 khi chủ tịch hội đồng quản trị không đồng thời là giám đốc. Sở hữu chéo một tình trạng khá phổ biến trong các doanh nghiệp niêm yết ở Việt Nam, sở hữu chéo thường dẫn đến rủi ro thiếu minh bạch trong quản trị và gây khó khăn cho sự quản lý từ các cơ quan chức năng, theo chúng tôi đây cũng là một nguyên nhân quan trọng đưa đến tình trạng kiệt quệ của các doanh nghiệp Việt Nam, biến giả "sở hữu chéo" nhận giá trị 1 khi công ty được sở hữu bởi một công ty niêm yết khác và ngược lại nhận giá trị 0 .

\subsection{Anh hưởng của truyền thông đến kiệt quệ tài chính}

Bên cạnh các biến số tài chính truyền thống, bắt đầu từ thập kỷ trước, tin tức truyền thông cũng đã được sử dụng nhiều trong các nghiên cứu về tài chính.

Chẳng hạn Tetlock (2007) đã phát hiện ra rằng nội dung đưa tin của phương tiện truyền thông có khả năng dự báo áp lực giảm giá trên thị trường của cổ phiếu. Tetlock, SaarTsechansky, và Macskassy (2008) đã phát hiện rằng các từ ngữ tiêu cực ở những tin tức cụ thể về một công ty có khả năng dự đoán sự sụt giảm về doanh thu, lợi nhuận, giá cổ phiếu của công ty này.

Gần đây, Engelberg và Parsons (2011) cho thấy phương tiện thông tin địa phương tác động mạnh mẽ đến các giao dịch trong nước. Tiếp đó nghiên cứu Demers và Vega (2014) chỉ ra thông tin từ truyền thông có ảnh hưởng đến lợi nhuận bất thường và hành vi nhà đầu tư.

Điều đó cho thấy khả năng có thể khai thác được của các thông tin từ truyền thông đồng thời chỉ ra khả năng dự báo của loại thông tin này tới tình hình của thị trường cũng như một công ty nào đó.

Đối với việc sử dụng tin tức truyền thông để dự báo kiệt quệ tài chính, trong thời gian gần đây, nhiều nhà nghiên cứu đã tiến hành thực hiện như Lu, Wei, và Chang (2015) xây dựng các biến đại diện cho tin tức từ truyền thông bằng các công thức khác nhau để đưa vào mô hình dự báo kiệt quệ tài chính cũng như xây dựng mô hình xếp hạng rủi ro vỡ nợ của các doanh nghiệp niêm yết trên 2 sàn chứng khoán TWSE và GTSM ở Đài Loan. Kết quả cho thấy tin tức truyền thông có ý nghĩa thống kê và thể hiện mức độ ảnh hưởng lớn trong việc dự báo sớm tình trạng vỡ nợ và xếp hạng rủi ro vỡ nợ của doanh nghiệp. Hay tại Việt Nam, kết quả nghiên cứu của Nguyen và Nguyen (2014) đã chỉ ra rằng các văn bản báo cáo thường niên và tin tức trực 
tuyến về các doanh nghiệp có ý nghĩa trong việc dự báo kiệt quệ tài chính và phát hiện gian lận báo cáo tài chính.

Như vậy các nhân tố phổ biến ảnh hưởng đến sự vỡ nợ của doanh nghiệp được đề xuất trong các nghiên cứu trước đây được chia thành 4 nhóm nhân tố gồm tình hình tài chính doanh nghiệp, quản trị doanh nghiệp, kinh tế vĩ mô và ảnh hưởng của truyền thông. Những biến này được chúng tôi sử dụng kết hợp với mô hình hồi quy logistic để dự báo xác suất vỡ nợ các doanh nghiệp.

\section{Dữ liệu và phương pháp nghiên cứu}

\subsection{Nguồn dũ liệu}

Dữ liệu về các công ty phi tài chính bị hủy niêm yết từ năm 2010 đến 2016 từ trang web của Sở giao dịch chứng khoán Thành phố Hồ Chí Minh bao gồm 60 công ty với nguyên nhân là lợi nhuận sau thuế âm trong 3 năm liên tiếp, có vốn chủ sở hữu âm hoặc bị phá sản, giải thể.

Theo đề xuất của một số bài nghiên cứu trước đây Beaver (1966), Lee và Yeh (2004), Lu và cộng sự (2015), xây dựng mẫu ghép đôi gồm các công ty kiệt quệ và không kiệt quệ theo tỷ lệ 1:3, tức là với một công ty kiệt quệ, sẽ có 3 công ty không kiệt quệ cùng ngành được chọn để ghép đôi. Tuy nhiên, do những ràng buộc về điều kiện chọn mẫu, số lượng các công ty không kiệt quệ được chọn chỉ đáp ứng được tỷ lệ 1:2.2, cụ thể chúng tôi thu thập thông tin của 108 công ty.

Biến tỷ số tài chính từ các báo cáo tài chính được thu thập từ trang web www.cophieu68.vn.

Biến quản trị doanh nghiệp được xây dựng thủ công từ việc tìm hiểu thông tin ban lãnh đạo, ban quản trị, cổ đông của từng công ty trong mẫu trên trang web www.cafef.vn và báo cáo thường niên của các doanh nghiệp.

Biến kinh tế vĩ mô được thu thập từ kho dữ liệu của ngân hàng thế giới. Các biến này được thu thập trong vòng 3 năm trước thời điểm xảy ra sự kiện kiệt quệ cho tới thời điểm xảy ra sự kiện kiệt quệ.

Đối với biến truyền thông, các tin tức được thu thập từ cổng điện tử www.cafef.vn. Đây là trang chuyên về kinh tế, tài chính; có lượng truy cập cao ở Việt Nam; số lượng bài viết rất lớn và đa dạng; tiêu đề các bài báo đưa tin về một doanh nghiệp luôn được bắt đầu với mã cổ phiếu của doanh nghiệp đó đồng thời, các tin tức được phân loại thành các mục, tạo ra sự dễ dàng, đầy đủ trong việc tìm kiếm và thu thập nội dung. Các bài báo của mỗi công ty được thu thập từ 3 năm trước thời điểm xảy ra sự kiện kiệt quệ cho đến cuối năm liền trước thời điểm kiệt quệ.

\section{2. Định lượng biến DIDC tù̀ báo cáo trên phương tiện truyền thông}

\subsubsection{Xây dựng danh sách tù đặc trung}

Theo đề xuất của Lu và cộng sự (2015), chúng tôi xây dựng biến "DIDC thuần" dựa vào tần số xuất hiện của các từ ngữ kiệt quệ và không kiệt quệ. Mỗi từ khóa chỉ nằm ở nhóm từ 
kiệt quệ hoặc nhóm từ không kiệt quệ bởi vì đây là 2 khái niệm trái ngược nhau hoàn toàn (Xem Hình 3.1)

Chúng tôi dùng kiểm định $\left(\chi^{2}\right)$ theo đề xuất của Yang và Pedersen (1997) để trích lọc ra các từ khóa đại diện cho kiệt quệ tài chính và không kiệt quệ. Hệ số $\left(\chi^{2}\right)$ càng cao thì từ khóa càng có tính đại diện cho một phân lớp nào đó.

\subsection{2. Đo lường DIDC}

Với dữ liệu truyền thông đã được xử lý, tôi xây dựng 4 biến DIDC bao gồm: DIDC (DIDC thuần), dmDIDC, $\triangle \mathrm{DIDC}$ và $\triangle \mathrm{dmDIDC}$. Công thức tính $\mathrm{DIDC}$ được biểu diễn như sau:

$$
D I D C_{i, t}=\frac{\sum_{a=1}^{A} W_{i t a}^{D}}{\sum_{b=1}^{A} W_{i t b}^{N D}}
$$

Trong đó: $D I D C_{i, t}$ mô tả "cường độ kiệt quệ được phản ánh trong tin tức" của công ty thứ i trong năm t. $W_{i t a}^{D}$ là tần số của từ khóa kiệt quệ thứ a của công ty i trong năm $\mathrm{t}$ và $W_{i t b}^{N D}$ tần số của từ khóa không kiệt quệ thứ b của công ty i trong năm thứ t. Nếu $W_{i t a}^{D}>W_{i t b}^{N D}$, khi đó DIDC sẽ lớn hơn 1 đồng nghĩa với việc các bài báo phản ánh một mức độ kiệt quệ rõ ràng.

Nội dung trên các tin tức truyền thông rõ ràng thường chịu ảnh hưởng bởi tình hình của nền kinh tế và thị trường; vì vậy, có thể có một số chênh lệch giữa các công ty kiệt quệ với mức độ "bình thường" trong phương pháp đo lường DIDC. Do đó, tôi xây dựng biến de-mean DIDC để mô tả độ lệch trong DIDC giữa mỗi công ty với giá trị trung bình như sau:

$$
d m D I D C_{i, t}=D I D C_{i, t}-\mu D I D C_{t}
$$

Trong đó $d m D I D C_{i, t}$ là biến mô tả độ lệch của DIDC với giá trị trung bình của công ty i trong năm $\mathrm{t}$ và $\mu D I D C_{t}$ là giá trị trung bình của tất cả các công ty kiệt quệ lẫn không kiệt quệ ở năm $\mathrm{t}$

Tiếp tục, một câu hỏi đặt ra là liệu rằng sự thay đổi DIDC theo năm của các công ty có tiết lộ điều gì về hoạt động kinh doanh hay tình hình tài chính của họ hay không. Do vậy, tôi xây dựng thêm 2 biến là $\triangle \mathrm{DIDC}$ và $\triangle \mathrm{dmDIDC}$ theo công thức sau:

$$
\Delta D I D C_{t}=D I D C_{t}-D I D C_{t-1}
$$

Và

$$
\Delta d m D I D C_{t}=d m D I D C_{t}-d m D I D C_{t-1}
$$




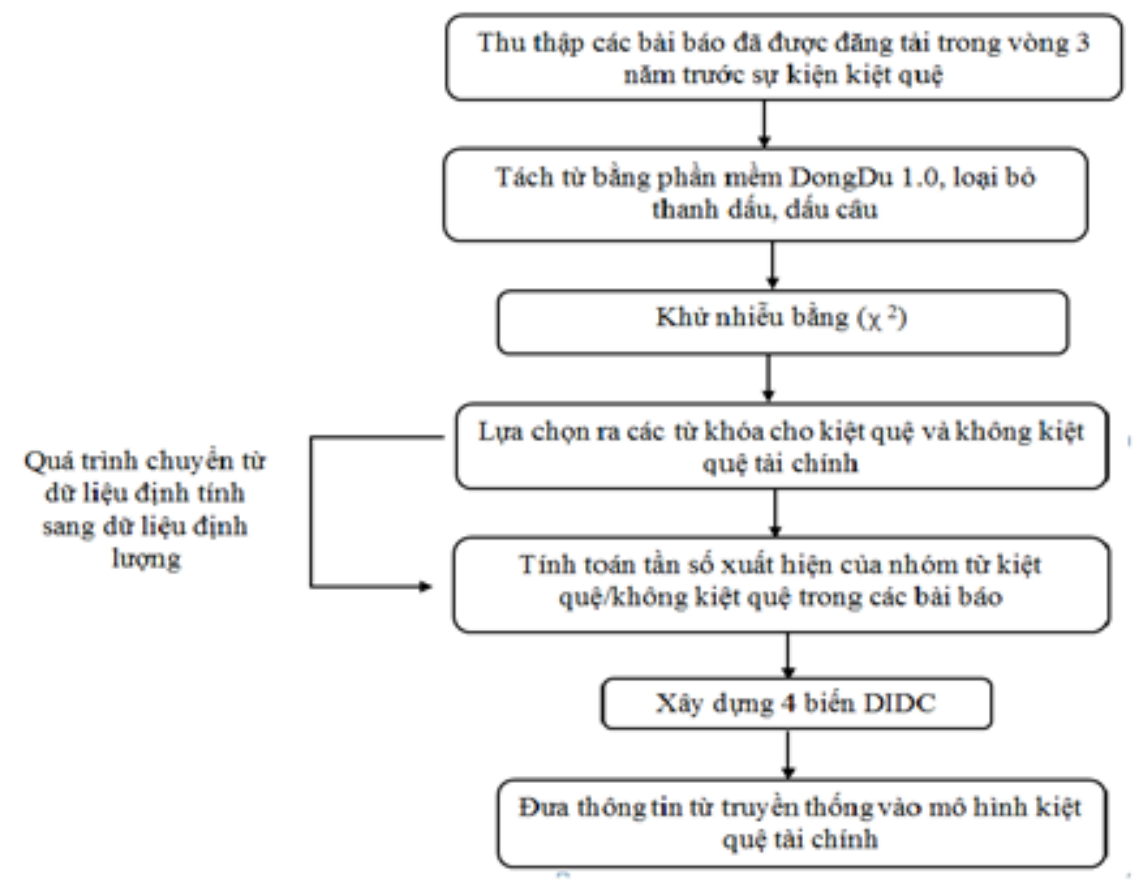

Hình 1. Quy trình xây dựng nhóm biến DIDC

\section{Bảng 1}

Các biến và cách xây dựng

\begin{tabular}{|c|c|c|}
\hline Biến & Định nghĩa & $\begin{array}{l}\text { Kỳ vọng } \\
\text { dấu }\end{array}$ \\
\hline \multicolumn{3}{|l|}{ Bảng A: Yếu tố tài chính } \\
\hline Tỷ số thanh khoản & Tài sản ngắn hạn chia nợ ngắn hạn & - \\
\hline Tỷ số thanh khoản nhanh & $\begin{array}{l}\text { Tài sản ngắn hạn trừ hàng tồn kho và tài sản ngắn } \\
\text { hạn khác chia nợ ngắn hạn }\end{array}$ & - \\
\hline $\begin{array}{l}\text { Tỷ số thanh khoản bằng tiền } \\
\text { mặt }\end{array}$ & Tiền mặt chia nợ ngắn hạn & - \\
\hline Tỷ lệ nợ & Tổng nợ chia tổng tài sản & + \\
\hline EPS & Lãi ròng trên một cổ phiếu & - \\
\hline Lợi nhuận trước thuế/doanh thu & Lợi nhuận trước thuế chia tổng doanh thu & - \\
\hline Hiệu quả sử dụng tài sản & Doanh thu chia tổng tài sản & - \\
\hline \multicolumn{3}{|c|}{ Bảng B: Các yếu tố quản trị doanh nghiệp } \\
\hline CEO & $\begin{array}{l}\text { Biến giả, bằng } 1 \text { khi giám đốc điều hành và chủ tịch } \\
\text { hội đồng quản trị là một người }\end{array}$ & + \\
\hline Sở hữu chéo & $\begin{array}{l}\text { Biến giả, bằng } 1 \text { nếu công ty được sở hữu bởi một } \\
\text { công ty niêm yết khác }\end{array}$ & + \\
\hline \multicolumn{3}{|l|}{ Bảng C: Các yếu tố vĩ mô } \\
\hline Tỷ lệ thất nghiệp & Phần trăm người thất nghiệp trong độ tuổi lao động & + \\
\hline Lạm phát & Sự tăng trưởng của chỉ số giá tiêu dùng CPI & \\
\hline \multicolumn{3}{|l|}{ Bảng D: Yếu tố truyền thông } \\
\hline DIDC & Mức độ phản ánh kiệt quệ tài chính trong văn bản & + \\
\hline
\end{tabular}

Nguồn: Kết quả phân tích dữ của nhóm nghiên cứu 


\subsection{Phương pháp}

Chúng tôi sử dụng mô hình logistic như trong nghiên cứu của Shumway (2001), Lu và cộng sự (2015) trong đó biến độc lập nhận 2 trường hợp kiệt quệ hoặc không kiệt quệ và được mã hóa thành 0 và 1 .

Gọi Y là biến mô tả một công ty có rơi vào tình trạng kiệt quệ tài chính hay không, khi đó Y chỉ nhận 2 giá trị là 1 (xảy ra tình trạng kiệt quệ) và 0 (không xảy ra tình trạng kiệt quệ). Biến phụ thuộc lúc này là biến rời rạc, để có thể thực hiện mô hình hồi quy, ta cần đổi biến số này về dạng liên tục. Gọi $\mathrm{p}$ là xác suất xảy ra tình trạng kiệt quệ tài chính, suy ra 1-p là xác suất biến cố kiệt quệ không xảy ra. Tỷ số $\frac{P}{1-P}$ được gọi là tỷ số Odds, đây là một biến số liên tục. Mô hình hồi quy logistic được xây dựng dựa trên khái niệm hàm logit, vế trái trong phương trình hồi quy logistic là $\operatorname{logit}(\mathrm{p})=\ln \left(\frac{P}{1-P}\right)$. Nếu $\ln \left(\frac{P}{1-P}\right)=\mathrm{f}(\mathrm{X})$ ta suy ra được $\mathrm{P}=\frac{e^{f(X)}}{1+e^{f(X)}}$

Dựa vào đó, phương trình hồi quy được sử dụng trong bài nghiên cứu này được phát biểu như sau:

$$
\ln \left(\frac{P_{i, t}}{1-P_{i, t}}\right)=\alpha_{0}+\alpha_{1} X_{i, t}+\beta D I D C_{i, t-k}
$$

- $P_{i, t}$ là xác suất công ty i rơi vào tình trạng kiệt quệ ở năm $\mathrm{t}$;

- X là véc-tơ của các biến giải thích bao gồm các tỷ số tài chính, nhóm biến quản trị doanh nghiệp và nhóm biến vĩ mô ;

- DIDC là biến đại diện cho thông tin được trích xuất từ các tin tức trực tuyến. $\mathrm{k}=1,2$ hoặc 3 .

Đầu tiên mô hình hồi quy đơn biến sẽ được thực hiện với từng biến riêng lẻ trong nhóm DIDC, sau đó 4 biến DIDC được đưa vào mô hình hồi quy cùng lúc để kiểm tra khả năng dự đoán của nhóm biến truyền thông. Tiếp tục, mô hình được thực hiện với các biến thuộc nhóm định lượng $(\mathrm{X})$. Tiếp đó, lần lượt từng biến riêng lẻ thuộc nhóm DIDC được kết hợp với nhóm biến $X$. Cuối cùng, tất cả các biến thuộc nhóm định lượng và DIDC được đưa vào mô hình đồng thời để kiểm tra mức độ giải thích cũng như khả năng dự báo của tất cả các nhân tố khi được kết hợp với nhau.

\section{4. Đánh giá độ chính xác của mô hình}

\subsubsection{Khả năng phân loại chính xác (CC)}

\section{Bảng 2}

Mức phân loại chính xác

\begin{tabular}{|c|c|c|l|}
\hline \multirow{2}{*}{ Thực tế } & \multicolumn{2}{|c|}{ Dự đoán của mô hình } & \multirow{2}{*}{ Khả năng dự báo } \\
\cline { 2 - 3 } & Không kiệt quệ $(\mathrm{Y}=0)$ & Kiệt quệ $(\mathrm{Y}=1)$ & \\
\hline Không kiệt quệ(Y=0) & $\mathrm{A}$ & $\mathrm{B}$ & $\mathrm{E}=\mathrm{A} /(\mathrm{A}+\mathrm{B})$ \\
\hline Kiệt quệ (Y=1) & $\mathrm{C}$ & $\mathrm{D}$ & $\mathrm{F}=\mathrm{D} /(\mathrm{C}+\mathrm{D})$ \\
\hline Tô̂ng & & & $\mathbf{G}=(\mathbf{A}+\mathrm{D}) /(\mathbf{A}+\mathbf{B}+\mathbf{C}+\mathrm{D})$ \\
\hline
\end{tabular}

Nguồn: Kết quả phân tích dữ của nhóm nghiên cứu 
Để có thể so sánh độ chính xác và khả năng dự báo của các mô hình từ đó tìm ra mô hình tốt nhất, tôi sử dụng chỉ số "Mức phân loại chính xác" (Correctly classified).

Mức phân loại chính xác của mô hình có liên quan đến các sai lầm loại I và sai lầm loại II. Cụ thể, mức phân loại chính xác được tính như sau:

$$
C C=\frac{A+C}{A+B+C+D}
$$

Với $A$ và $D$ là các trường hợp mô hình dự báo đúng cho công ty kiệt quệ và công ty không kiệt quệ, $\mathrm{B}$ và $\mathrm{C}$ lần lượt là các sai lầm loại II và loại $\mathrm{I}$. Như vậy $\mathrm{CC}$ mô tả khả năng dự báo tổng quát của mô hình đối với cả công ty kiệt quệ và công ty không kiệt quệ nói chung.

\subsubsection{Hiệu quả dụ báo theo trọng số}

Theo Korobow và Stuhr (1985), chúng tôi sử dụng chỉ số "hiệu quả dự báo có trọng số" theo công thức như sau:

$$
W E=\frac{D}{B+D} \times \frac{D}{C+D} \times C C
$$

- WE là chỉ số "hiệu quả dự báo có trọng số" của từng mô hình;

- D là số công ty kiệt quệ được mô hình dự báo đúng;

- $\quad(B+D)$ số công ty được mô hình dự báo là kiệt quệ;

- $(\mathrm{C}+\mathrm{D})$ là tổng số công ty bị kiệt quệ trên thực tế.

\section{Kết quả thực nghiệm}

\subsection{Thống kê mô tả các biến định lự̣ng}

\section{Bảng 3}

\begin{tabular}{|c|c|c|c|c|c|c|c|c|c|c|}
\hline \multirow[b]{2}{*}{ Các biến } & \multirow[b]{2}{*}{ Nhóm } & \multicolumn{3}{|c|}{ Mean } & \multicolumn{3}{|c|}{ Minimum } & \multicolumn{3}{|c|}{ Maximum } \\
\hline & & $\begin{array}{c}1 \\
\text { năm }\end{array}$ & $\begin{array}{c}2 \\
\text { năm }\end{array}$ & $\begin{array}{c}\mathbf{3} \\
\text { năm }\end{array}$ & $\begin{array}{c}1 \\
\text { năm }\end{array}$ & $\begin{array}{c}2 \\
\text { năm }\end{array}$ & $\begin{array}{c}3 \\
\text { năm }\end{array}$ & $\begin{array}{c}1 \\
\text { năm }\end{array}$ & $\underset{\text { năm }}{2}$ & $\begin{array}{c}\mathbf{3} \\
\text { năm }\end{array}$ \\
\hline \multirow{2}{*}{$\begin{array}{l}\text { Tỷ số thanh } \\
\text { khoản }\end{array}$} & 1 & 1.52 & 1.44 & 1.83 & 0.1 & 0.17 & 0.15 & 18.18 & 25.67 & 34.11 \\
\hline & 0 & 1.72 & 1.71 & 1.82 & 0.24 & 0.42 & 0.23 & 7.18 & 7.68 & 6.52 \\
\hline \multirow{2}{*}{$\begin{array}{l}\text { Tỷ số thanh } \\
\text { khoản nhanh }\end{array}$} & 1 & 0.92 & 0.8 & 1.15 & 0.02 & 0.01 & 0.08 & 17.82 & 17.41 & 26.22 \\
\hline & 0 & 1.06 & 1.09 & 1.18 & 0.04 & 0.04 & 0.05 & 6.18 & 5.93 & 6.39 \\
\hline \multirow{2}{*}{$\begin{array}{l}\text { Tỷ số thanh } \\
\text { khoản bằng } \\
\text { tiền mặt }\end{array}$} & 1 & 0.06 & 0.07 & 0.08 & 0 & 0 & 0.00 & 0.61 & 0.54 & 0.50 \\
\hline & 0 & 0.17 & 0.17 & 0.19 & 0 & 0 & 0.00 & 0.84 & 0.95 & 0.96 \\
\hline \multirow{2}{*}{ Tỷ lệ nộ } & 1 & 0.82 & 0.73 & 0.67 & 0.03 & 0.01 & 0.01 & 1.6 & 0.98 & 0.95 \\
\hline & 0 & 0.52 & 0.52 & 0.51 & 0.07 & 0.06 & 0.04 & 0.91 & 0.93 & 0.87 \\
\hline \multirow{2}{*}{ EPS } & 1 & $\begin{array}{c}- \\
5.32\end{array}$ & -2.41 & -1.14 & $\begin{array}{c}- \\
33.51\end{array}$ & $\begin{array}{c}- \\
11.09\end{array}$ & $\begin{array}{c}- \\
15.79\end{array}$ & 0.81 & 1.05 & 5.45 \\
\hline & 0 & 1.23 & 1.32 & 1.54 & -4.73 & -8.04 & -2.05 & 11.6 & 7.14 & 7.13 \\
\hline $\begin{array}{l}\text { Lọii nhuận } \\
\text { trước }\end{array}$ & 1 & $\overline{-}-$ & -0.35 & -0.18 & $\begin{array}{c}- \\
16.98\end{array}$ & -2.45 & -2.25 & 0.04 & 0.03 & 0.05 \\
\hline
\end{tabular}

Thống kê mô tả các biến định lượng 


\begin{tabular}{|c|c|c|c|c|c|c|c|c|c|c|}
\hline \multirow{3}{*}{$\begin{array}{l}\text { Các biến } \\
\text { thuế/Doanh } \\
\text { thu }\end{array}$} & \multirow[b]{2}{*}{ Nhóm } & \multicolumn{3}{|c|}{ Mean } & \multicolumn{3}{|c|}{ Minimum } & \multicolumn{3}{|c|}{ Maximum } \\
\hline & & $\begin{array}{c}1 \\
\text { năm }\end{array}$ & $\begin{array}{c}2 \\
\text { năm }\end{array}$ & $\begin{array}{c}3 \\
\text { năm }\end{array}$ & $\begin{array}{c}1 \\
\text { năm }\end{array}$ & $\begin{array}{c}2 \\
\text { năm }\end{array}$ & $\begin{array}{c}3 \\
\text { năm }\end{array}$ & $\begin{array}{c}1 \\
\text { năm }\end{array}$ & $\begin{array}{c}2 \\
\text { năm }\end{array}$ & $\begin{array}{c}3 \\
\text { năm }\end{array}$ \\
\hline & 0 & $\overline{-}$ & -0.28 & -0.16 & -9.28 & $\begin{array}{c}- \\
34.66 \\
\end{array}$ & $\begin{array}{c}- \\
23.72 \\
\end{array}$ & 1.3 & 1.34 & 0.50 \\
\hline \multirow{2}{*}{$\begin{array}{l}\text { Doanh } \\
\text { thu/tài sản }\end{array}$} & 1 & 0.63 & 0.66 & -0.05 & 0 & 0.01 & -0.83 & 3.37 & 2.31 & 0.03 \\
\hline & 0 & 1.23 & 1.23 & 0.06 & 0 & 0 & -0.19 & 5.24 & 5.08 & 0.49 \\
\hline \multirow{2}{*}{ CEO } & 1 & 0.39 & 0.41 & 0.33 & 0 & 0 & 0.00 & 1 & 1 & 1.00 \\
\hline & 0 & 0.22 & 0.21 & 0.26 & 0 & 0 & 0.00 & 1 & 1 & 1.00 \\
\hline \multirow{2}{*}{ Sở hữu chéo } & 1 & 0.14 & 0.14 & 0.12 & 0 & 0 & 0.00 & 1 & 1 & 1.00 \\
\hline & 0 & 0.21 & 0.21 & 0.23 & 0 & 0 & 0.00 & 1 & 1 & 1.00 \\
\hline \multirow{2}{*}{ Lạm phát } & 1 & 9.52 & 10.69 & 11.69 & 0 & 4.09 & 6.59 & 51.08 & 18.68 & 23.12 \\
\hline & 0 & 8.06 & 11.94 & 11.13 & 0.63 & 4.09 & 6.59 & 18.68 & 18.68 & 23.12 \\
\hline \multirow{2}{*}{ Thất nghiệp } & 1 & 2.08 & 2.07 & 2.23 & 1.8 & 1.8 & 1.80 & 2.6 & 2.6 & 2.60 \\
\hline & 0 & 2.05 & 2.06 & 2.30 & 1.8 & 1.8 & 1.80 & 2.6 & 2.6 & 2.60 \\
\hline
\end{tabular}

Nguồn: Kết quả phân tích dữ liệu của nhóm nghiên cứu

Đối với các tỷ số tài chính, ở nhóm biến tỷ số thanh khoản, có thể thấy rằng tất cả các giá trị trung bình và giá trị nhỏ nhất của nhóm công ty không kiệt quệ đều cao hơn nhóm công ty kiệt quệ ở cả thời điểm 1 lẫn 2 năm trước sự kiện. Điều này có thể ám chỉ rằng mức thanh khoản cao có thể góp phần giúp công ty trở nên an toàn hơn trước nguy cơ kiệt quệ. Kết quả tương tự với tỷ số lợi nhuận trước thuế/doanh thu và doanh thu/tài sản. Như vậy nhóm công ty kiệt quệ có các chỉ số EPS, lợi nhuận trước thuế/doanh thu, doanh thu/tài sản nhìn chung là thấp hơn so với nhóm công ty không kiệt quệ.

Giá trị trung bình của biến $\mathrm{CEO}$ cũng chỉ ra rằng vấn đề tập trung quyền lực thường xuất hiện nhiều hơn ở nhóm công ty kiệt quệ. Trong khi đó, biến tỷ lệ sở hữu chéo lại có thống kê không theo kỳ vọng khi kết quả thống kê cho thấy hiện tượng sở hữu chéo xuất hiện nhiều hơn ở nhóm công ty không kiệt quệ.

Đối với biến lạm phát, chỉ qua kết quả thống kê mô tả thì vẫn chưa xác định ảnh hưởng của lạm phát đến tình trạng kiệt quệ tài chính một cách rõ ràng được. Biến thất nghiệp có kết quả thống kê mô tả hỗ trợ cho kỳ vọng dấu khi nhóm các công ty kiệt quệ có giá trị biến thất nghiệp cao hơn nhóm công ty không kiệt quệ.

Nhìn chung, hầu hết các giá trị thống kê của các biến khi đem so sánh giữa nhóm công ty kiệt quệ với nhóm công ty không kiệt quệ đều hỗ trợ cho những kỳ vọng dấu bài nghiên cứu này đã đặt ra.

\section{Bảng 4}

\subsection{Thống kê mô tả và tương quan biến DIDC}

Thống kê mô tả biến DIDC

\begin{tabular}{lcccccccccc}
\hline \multirow{2}{*}{ Các biến } & \multirow{2}{*}{ Nhóm } & \multicolumn{4}{c}{ Mean } & \multicolumn{4}{c}{ Minimum } & \multicolumn{4}{c}{ Maximum } \\
\cline { 3 - 11 } & & $\begin{array}{c}\mathbf{1} a ̆ m \\
\text { năm }\end{array}$ & $\begin{array}{c}\mathbf{3} \\
\text { năm }\end{array}$ & $\begin{array}{c}\mathbf{1} \\
\text { năm }\end{array}$ & $\begin{array}{c}\mathbf{2} \\
\text { năm }\end{array}$ & $\begin{array}{c}\mathbf{3} \\
\text { năm }\end{array}$ & $\begin{array}{c}\mathbf{1} \\
\text { năm }\end{array}$ & $\begin{array}{c}\mathbf{2} \\
\text { năm }\end{array}$ & $\begin{array}{c}\mathbf{3} \\
\text { năm }\end{array}$ \\
\hline \multirow{2}{*}{$\mathrm{DIDC}$} & 1 & 4.34 & 1.89 & 0.55 & 0.55 & 0.23 & 0.00 & 5.48 & 24.20 & 3.43 \\
\hline & 0 & 0.81 & 0.77 & 0.25 & 0.04 & 0.00 & 0.00 & 4.83 & 4.90 & 1.68 \\
\hline
\end{tabular}




\begin{tabular}{|c|c|c|c|c|c|c|c|c|c|c|}
\hline \multirow{2}{*}{ Các biến } & \multirow[b]{2}{*}{ Nhóm } & \multicolumn{2}{|c|}{ Mean } & \multicolumn{3}{|c|}{ Minimum } & \multicolumn{4}{|c|}{ Maximum } \\
\hline & & $\begin{array}{c}1 \\
\text { năm }\end{array}$ & $\begin{array}{c}2 \\
\text { năm }\end{array}$ & $\begin{array}{c}\mathbf{3} \\
\text { năm }\end{array}$ & $\begin{array}{c}1 \\
\text { năm }\end{array}$ & $\begin{array}{c}2 \\
\text { năm }\end{array}$ & $\begin{array}{c}\mathbf{3} \\
\text { năm }\end{array}$ & $\begin{array}{c}1 \\
\text { năm }\end{array}$ & $\begin{array}{c}2 \\
\text { năm }\end{array}$ & $\begin{array}{c}\mathbf{3} \\
\text { năm }\end{array}$ \\
\hline \multirow{2}{*}{$\mathrm{dmDIDC}$} & 1 & 2.70 & 0.43 & 0.11 & -1.27 & -2.06 & -0.56 & 3.70 & 21.44 & 3.08 \\
\hline & 0 & -0.75 & -0.56 & -0.17 & -2.53 & -2.63 & -0.71 & 3.06 & 2.23 & 1.34 \\
\hline \multirow{2}{*}{$\triangle \mathrm{DIDC}$} & 1 & 2.47 & 0.64 & & -2.22 & -4.19 & & 4.62 & 21.23 & \\
\hline & 0 & 0.08 & 0.19 & & -2.86 & -2.95 & & 2.65 & 4.57 & \\
\hline \multirow[b]{2}{*}{$\triangle \mathrm{dmDIDC}$} & 1 & 2.21 & 0.24 & & -2.72 & -4.23 & & 4.23 & 20.25 & \\
\hline & 0 & -0.22 & -0.15 & & -3.84 & -3.54 & & 2.27 & 3.59 & \\
\hline
\end{tabular}

Nguồn: Kết quả phân tích dữ liệu của nhóm nghiên cứu

Giá trị trung bình và giá trị lớn nhất của biến DIDC, dmDIDC ở nhóm công ty kiệt quệ cao hơn so với nhóm không kiệt quệ. Kết quả này cho thấy phương tiện truyền thông có những tín hiệu tiêu cực xuất hiện trước sự kiện kiệt quệ của công ty đó, từ đó có thể xem phương tiện truyền thông là một kênh thông tin có khả năng đưa ra những cảnh báo cho những dấu hiệu vỡ nợ tiềm tàng. Sự thay đổi trong DIDC và dmDIDC của nhóm công ty kiệt quệ cũng cao hơn rất nhiều so với nhóm công ty không kiệt quệ cho thấy các công ty kiệt quệ có mức độ biến động về sắc thái của tin tức trực tuyến trước thời điểm kiệt quệ là rất lớn trong khi nhóm công ty không kiệt quệ hầu như không có nhiều sự biến động trong DIDC.

\section{Bảng 5}

Tương quan giữa biến DIDC và các biến thể trong 1, 2, 3 năm trước sự kiện phá sản

\begin{tabular}{|c|l|c|c|c|c|}
\hline & & DIDC & dmDIDC & $\Delta$ DIDC & $\Delta$ dmDIDC \\
\hline \multirow{4}{*}{ Năm 1 } & DIDC & 1 & $0.988^{* *}$ & $0.941^{* *}$ & $0.921^{* *}$ \\
\cline { 2 - 6 } & dmDIDC & $0.988^{* *}$ & 1 & $0.937^{* *}$ & $0.926^{* *}$ \\
\cline { 2 - 6 } & $\triangle$ DIDC & $0.941^{* *}$ & $0.937^{* *}$ & 1 & $0.978^{* *}$ \\
\cline { 2 - 6 } & $\triangle$ dm DIDC & $0.941^{* *}$ & $0.926^{* *}$ & $0.978^{* *}$ & 1 \\
\hline \multirow{4}{*}{ Năm 2 } & DIDC & 1 & $0.835^{* *}$ & $0.670^{* *}$ & $0.618^{* *}$ \\
\cline { 2 - 6 } & dmDIDC & $0.835^{* *}$ & 1 & $0.546^{* *}$ & $0.675^{* *}$ \\
\cline { 2 - 6 } & $\triangle$ DIDC & $0.670^{* *}$ & $0.546^{* *}$ & 1 & $0.940^{* *}$ \\
\cline { 2 - 6 } & $\triangle$ dm DIDC & $0.618^{* *}$ & $0.675^{* *}$ & $0.940^{* *}$ & 1 \\
\hline \multirow{2}{*}{ Năm 3 } & DIDC & 1 & $0.910^{* *}$ & & \\
\cline { 2 - 6 } & dmDIDC & $0.910^{* *}$ & 1 & & \\
\hline
\end{tabular}

$*, * *, * * *$ tương ứng với mức $\mathrm{p}$-value là $10 \%, 5 \%$ và $1 \%$

Nguồn: Kết quả phân tích dữ liệu của nhóm nghiên cứu

Do kỹ thuật xây dựng biến nên tương quan giữa biến DIDC và các biến thể của DIDC cao và có ý nghĩa thống kê, nhóm tác giả sẽ lần lượt đưa từng biến vào mô hình để kiểm tra ảnh hưởng của biến truyền thông cũng như sự dai dẳng của yếu tố này đến xác suất kiệt quệ của doanh nghiệp niêm yết.

\subsection{Kết quả hồi quy logistic}

\subsubsection{Mô hình dụ báo kiệt quệ tài chính}

Kết quả cho thấy khi được hồi quy riêng lẻ, các biến DIDC đơn lẻ đều có ý nghĩa thống kê ở mức 1\% qua các năm (Mô hình 1, 2, 3 và 4 trong Bảng 5). Bên cạnh đó, hệ số của các biến 
thuộc nhóm DIDC khi được hồi quy riêng lẻ đều là số dương. Điều này có nghĩa rằng với một sự gia tăng chỉ số DIDC sẽ dẫn đến khả năng kiệt quệ của công ty là cao hơn.

\section{Bảng 6}

Kết quả hồi quy nhóm biến DIDC

\begin{tabular}{|c|c|c|c|c|c|c|}
\hline \multirow{2}{*}{ Năm } & \multirow{2}{*}{ Biến } & \multicolumn{5}{|c|}{ Mô hình } \\
\hline & & (1) & (2) & (3) & (4) & (5) \\
\hline \multirow{5}{*}{1 năm } & Hằng số & $-2.946 * * *$ & $-0.806 * * *$ & $-1.234 * * *$ & $-1.045 * * *$ & $-2.073 * * *$ \\
\hline & DIDC & $1.379 * * *$ & - & - & - & $1.023 * *$ \\
\hline & $\mathrm{dmDIDC}$ & - & $1.398 * * *$ & - & - & 0.849 \\
\hline & $\triangle \mathrm{DIDC}$ & - & - & $0.711 * * *$ & - & $-0.844^{*}$ \\
\hline & $\triangle \mathrm{dmDIDC}$ & - & - & - & $0.663 * * *$ & 0.299 \\
\hline \multirow{5}{*}{2 năm } & Hằng số & $-1.957 * * *$ & $-0.647 * * *$ & $-0.906 * * *$ & $-0.747 * * *$ & $-2.327 * * *$ \\
\hline & DIDC & $1.023 * * *$ & - & - & - & $1.466 * *$ \\
\hline & $\mathrm{dmDIDC}$ & - & $0.738 * * *$ & - & - & -0.169 \\
\hline & $\triangle \mathrm{DIDC}$ & - & - & $0.436 * * *$ & - & -0.561 \\
\hline & $\triangle \mathrm{dmDIDC}$ & - & - & - & $0.381 * * *$ & 0.119 \\
\hline \multirow{3}{*}{3 năm } & Hằng số & $-1.526 * * *$ & $-0.619 * * *$ & - & - & $-1.632 * * *$ \\
\hline & DIDC & $0.927 * * *$ & - & - & - & $1.027 * * *$ \\
\hline & dmDIDC & - & $0.778 * * *$ & - & - & $-0.110 * * *$ \\
\hline
\end{tabular}

*, **, *** tương ứng với mức p-value là $10 \%, 5 \%$ và $1 \%$

Ghi chú: Ở bảng kết quả hồi quy 3 năm, không có biến $\triangle \mathrm{DIDC}$ và $\triangle \mathrm{dmDIDC}$ vì giới hạn dữ liệu

Nguồn: Kết quả xử lý dữ liệu của nhóm nghiên cứu

Khi kết hợp cả 4 biến DIDC vào mô hình 5 , kết quả đã cho thấy biến DIDC có ý nghĩa thống kê ở mức $5 \%$ và hệ số beta cao hơn đáng kể so với các biến tin tức truyền thông khác. Điều này thể hiện vai trò dẫn dắt của biến DIDC khi kết hợp cùng các biến còn lại.

Bảng 6 thể hiện kết quả hồi quy kết hợp các biến định lượng với các biến tin tức truyền thông. Theo đó, một mức EPS cao làm giảm nguy cơ kiệt quệ tài chính nhưng mức lạm phát cao làm xác suất kiệt quệ gia tăng. Đối với thời điểm 2 năm tỷ lệ thanh khoản bằng tiền mặt cao, tỷ lệ nợ cao, thất nghiệp cao làm gia tăng xác suất kiệt quệ tài chính và một mức EPS cao làm giảm xác suất kiệt quệ tài chính. Ở thời điểm 3 năm trước sự kiệt quệ, các kết quả này là đúng với kỳ vọng dấu đồng thời cũng chỉ ra rằng các biến có ý nghĩa thống kê nằm ở nhóm biến tỷ số tài chính và kinh tế vĩ mô.

Đối với nhóm biến tin tức truyền thông, các biến DIDC và dmDIDC có ý nghĩa thống kê trong các mô hình từ (6) đến (10) cho cả 1,2 và 3 năm trước kiệt quệ khi được kết hợp riêng lẻ với nhóm biến định lượng. Ở mô hình (11) khi kết hợp tất cả các biến để hồi quy mô hình, chỉ có DIDC có ý nghĩa thống kê. Nhìn chung các kết quả hồi quy ủng hộ cho quan điểm tin tức truyền thống có khả năng lý giải cho tình trạng kiệt quệ tài chính đặc biệt khi được sử dụng riêng lẻ từng biến. 


\subsubsection{Khả năng dụ báo của các mô hình}

Chúng tôi sử dụng 2 điểm mốc (cut-off) để phân loại các công ty trong mẫu nghiên cứu vào nhóm kiệt quệ hay không kiệt quệ từ đó tính ra các chỉ số $\mathrm{CC}$ và WE. Điểm mốc thứ nhất là 0.5 tức là một công ty sẽ được xếp vào nhóm công ty kiệt quệ khi kết quả xác suất được tính ra nhờ mô hình đã xây dựng lớn hơn hoặc bằng 0.5 , trong trường hợp còn lại, công ty được xếp vào nhóm không kiệt quệ. Điểm mốc thứ hai theo đề xuất của Martin (1977) được tính toán bằng cách lấy tổng số công ty trong nhóm kiệt quệ chia cho tổng số công ty trong mẫu. Tỷ lệ các công ty kiệt quệ/mẫu nghiên cứu trong các mô hình 1 năm trước kiệt quệ là $32.4 \%, 2$ năm trước kiệt quệ là $35 \%$ và $31.85 \%$ cho 3 năm trước kiệt quệ.

Ở thời gian 1 năm trước kiệt quệ, mô hình dự báo có hiệu quả dự đoán cao nhất đạt mức chính xác $94.5 \%$ trong khi ở thời điểm 2 năm trước kiệt quệ, con số này là $90 \%$. Với dữ liệu 3 năm trước năm kiệt quệ, mức độ chính xác của các mô hình đã giảm xuống tuy nhiên vẫn đạt được mức độ chính xác khá cao với $86 \%$ cho mô hình tối ưu nhất. 


\section{Bảng 7}

Kết quả dự báo kiệt quệ tài chính 1, 2, 3 năm trước sự kiện kiệt quệ

\begin{tabular}{|c|c|c|c|c|c|c|c|c|c|c|c|c|c|c|c|c|}
\hline & \multicolumn{3}{|c|}{ MH 6} & \multicolumn{3}{|c|}{ MH 7} & \multicolumn{3}{|c|}{ MH 8} & \multicolumn{2}{|c|}{ MH 9} & \multicolumn{2}{|c|}{ MH 10} & \multicolumn{3}{|c|}{ MH 11} \\
\hline & Năm 1 & Năm 2 & Năm 3 & Năm 1 & Năm 2 & Năm 3 & Năm 1 & Năm 2 & Năm 3 & Năm 1 & Năm 2 & Năm 1 & Năm 2 & Năm 1 & Năm 2 & Năm 3 \\
\hline Hằng số & -3.11 & $-7.64 * * *$ & $-5.33 *$ & -6.09 & $-8.74 * * *$ & $-5.61 *$ & -4.41 & $-6.90 * *$ & -4.47 & -3.49 & $-8.48 * * *$ & -2.87 & $-7.81 * * *$ & -10.16 & -6.61 & -9.29 \\
\hline $\begin{array}{l}\text { Tỷ số thanh } \\
\text { khoản }\end{array}$ & 0.50 & -0.02 & 0.45 & 0.71 & 0.08 & 0.35 & 0.61 & 0.11 & 0.35 & 0.53 & 0.04 & 0.53 & 0.03 & 0.88 & -0.09 & 0.42 \\
\hline $\begin{array}{l}\text { Tỷ số thanh } \\
\text { khoản nhanh }\end{array}$ & -0.29 & 0.26 & -0.15 & -0.51 & 0.01 & -0.04 & -0.43 & 0.01 & -0.04 & -0.37 & 0.14 & -0.37 & 0.16 & -0.60 & 0.26 & -0.12 \\
\hline $\begin{array}{l}\text { Thanh khoản } \\
\text { tiền mặt }\end{array}$ & 0.89 & $-4.76^{* *}$ & $-3.69 *$ & 1.16 & $-4.68 *$ & $-3.89 * *$ & 0.89 & $-4.69 *$ & $-3.89 * *$ & 1.04 & $-4.74 * *$ & 0.95 & $-4.75^{* *}$ & 0.83 & $-4.91 *$ & $-3.72 *$ \\
\hline Tỷ lệ nọ̆ & 0.07 & $3.67 * * *$ & $4.64 * * *$ & 0.51 & $3.29 * *$ & $4.44 * * *$ & 0.08 & $3.39 * *$ & $4.49 * * *$ & -0.11 & $3.57 * * *$ & -0.18 & $3.58 * * *$ & 0.24 & $3.30 * *$ & $4.43 * * *$ \\
\hline EPS & $-1.24 * * *$ & $-0.89 * * *$ & $-0.74 * * *$ & $-1.08 * * *$ & $-0.76^{* * *}$ & $-0.65 * * *$ & $-1.05 * * *$ & $-0.78 * * *$ & $0.67^{-} * * *$ & $-1.14 * * *$ & $-0.89 * * *$ & $-1.15^{* * *}$ & $-0.89 * * *$ & $-1.38^{* * * *}$ & $-0.73 * * *$ & $-0.64 * * *$ \\
\hline $\begin{array}{l}\text { LNTT/Doanh } \\
\text { thu }\end{array}$ & -0.29 & 0.10 & 0.20 & -0.29 & 0.19 & 0.22 & -0.23 & 0.17 & 0.22 & -0.32 & 0.13 & -0.29 & 0.13 & $-0.49 *$ & 0.20 & 0.21 \\
\hline $\begin{array}{l}\text { Doanh thu/tài } \\
\text { sản }\end{array}$ & -0.56 & -0.40 & $-0.62 *$ & -0.26 & -0.27 & $-0.65 *$ & -0.47 & -0.32 & $-0.65^{*}$ & -0.48 & -0.30 & -0.52 & -0.32 & 0.35 & -0.34 & $-0.65^{*}$ \\
\hline CEO & 0.33 & 0.86 & 0.65 & 0.39 & 0.81 & 0.58 & 0.45 & 0.89 & 0.60 & 0.40 & 0.90 & 0.39 & 0.91 & 0.49 & 0.81 & 0.54 \\
\hline Sở hữu chéo & -0.86 & -0.38 & -0.36 & -0.70 & -0.82 & -0.26 & -0.68 & -0.64 & -0.28 & -0.73 & -0.54 & -0.80 & -0.50 & -1.29 & -0.77 & -0.28 \\
\hline Lạm phát & $0.13 * *$ & 0.07 & 0.03 & $0.18^{* *}$ & 0.08 & 0.04 & $0.12 *$ & 0.02 & 0.02 & $0.14 * *$ & 0.08 & $0.13^{*}$ & 0.07 & $0.38^{* * * *}$ & 0.08 & 0.10 \\
\hline Thất nghiệp & -0.09 & $1.98^{*}$ & 0.98 & 0.07 & $2.14 *$ & 1.01 & 0.58 & $2.03^{*}$ & 0.75 & 0.05 & $2.30 *$ & -0.12 & $2.10^{*}$ & -0.69 & 0.55 & 1.91 \\
\hline DIDC & - & & & $1.02 * * *$ & $0.77 * * *$ & 0.34 & - & - & - & - & - & - & - & $2.96^{*}$ & 2.34 & 1.21 \\
\hline dmDIDC & - & & & - & & & $0.83 * * *$ & $0.62 * *$ & 0.25 & - & - & - & - & -1.29 & -1.42 & -0.86 \\
\hline rDIDC & - & & & - & & & - & - & - & 0.25 & 0.27 & - & - & 0.07 & -2.53 & - \\
\hline rdmDIDC & - & & & - & & & - & - & - & - & - & 0.17 & 0.24 & -0.92 & 2.26 & - \\
\hline
\end{tabular}

$*, * *, * * *$ tương ứng với mức $\mathrm{p}$-value là $10 \%, 5 \%$ và $1 \%$

Nguồn: Kết quả xử lý dữ liệu của nhóm nghiên cứu 


\section{Bảng 8}

Mức độ dự báo chính xác của các mô hình

\begin{tabular}{|c|c|c|c|c|c|c|c|c|c|c|c|c|}
\hline & & \multicolumn{11}{|c|}{ Mô hình } \\
\hline & & 1 & 2 & 3 & 4 & 5 & 6 & 7 & 8 & 9 & 10 & 11 \\
\hline \multirow{8}{*}{$\underset{\text { năm }}{1}$} & SLL1 & $37.3 \%$ & $37.3 \%$ & $62.7 \%$ & $57.6 \%$ & $35.6 \%$ & $12.1 \%$ & $10.3 \%$ & $12.1 \%$ & $13.8 \%$ & $13.8 \%$ & $10.3 \%$ \\
\hline & SLL2 & $5.7 \%$ & $5.7 \%$ & $4.1 \%$ & $3.3 \%$ & $7.4 \%$ & $4.1 \%$ & $3.3 \%$ & $4.1 \%$ & $2.5 \%$ & $2.5 \%$ & $4.1 \%$ \\
\hline & $\mathrm{CC}$ & $84.1 \%$ & $84.1 \%$ & $76.8 \%$ & $79.0 \%$ & $83.4 \%$ & $93.3 \%$ & $94.4 \%$ & $93.3 \%$ & $93.9 \%$ & $93.9 \%$ & $93.9 \%$ \\
\hline & WE & $44.3 \%$ & $44.3 \%$ & $23.3 \%$ & $28.9 \%$ & $43.4 \%$ & $74.7 \%$ & $78.6 \%$ & $74.7 \%$ & $76.3 \%$ & $76.3 \%$ & $76.8 \%$ \\
\hline & SLL1 & $22.0 \%$ & $22.0 \%$ & $35.6 \%$ & $33.9 \%$ & $18.6 \%$ & $12.1 \%$ & $8.6 \%$ & $10.3 \%$ & $12.1 \%$ & $12.1 \%$ & $8.6 \%$ \\
\hline & SLL2 & $11.4 \%$ & $9.8 \%$ & $10.7 \%$ & $18.0 \%$ & $13.9 \%$ & $6.6 \%$ & $4.9 \%$ & $7.4 \%$ & $7.4 \%$ & $7.4 \%$ & $6.6 \%$ \\
\hline & $\mathrm{CC}$ & $85.2 \%$ & $86.3 \%$ & $81.2 \%$ & $76.8 \%$ & $84.5 \%$ & $91.7 \%$ & $93.9 \%$ & $91.7 \%$ & $91.1 \%$ & $91.1 \%$ & $92.7 \%$ \\
\hline & WE & $50.9 \%$ & $53.3 \%$ & $39.0 \%$ & $32.5 \%$ & $50.8 \%$ & $69.7 \%$ & $77.1 \%$ & $70.1 \%$ & $68.1 \%$ & $68.1 \%$ & $73.6 \%$ \\
\hline \multirow{8}{*}{$\underset{\text { năm }}{2}$} & SLL1 & $59.6 \%$ & $65.4 \%$ & $86.5 \%$ & $90.4 \%$ & $57.7 \%$ & $30.8 \%$ & $26.9 \%$ & $26.9 \%$ & $26.9 \%$ & $28.8 \%$ & $23.1 \%$ \\
\hline & SLL2 & $10.2 \%$ & $8.3 \%$ & $2.8 \%$ & $1.9 \%$ & $8.3 \%$ & $6.5 \%$ & $9.3 \%$ & $9.3 \%$ & $6.5 \%$ & $6.5 \%$ & $8.4 \%$ \\
\hline & $\mathrm{CC}$ & $73.8 \%$ & $73.1 \%$ & $70.0 \%$ & $69.4 \%$ & $75.6 \%$ & $85.5 \%$ & $84.9 \%$ & $84.9 \%$ & $86.8 \%$ & $86.2 \%$ & $86.8 \%$ \\
\hline & WE & $19.5 \%$ & $16.9 \%$ & $6.6 \%$ & $4.8 \%$ & $22.7 \%$ & $49.6 \%$ & $49.1 \%$ & $49.1 \%$ & $53.6 \%$ & $51.6 \%$ & $54.5 \%$ \\
\hline & SLL1 & $38.5 \%$ & $44.2 \%$ & $51.9 \%$ & $55.8 \%$ & $34.6 \%$ & $17.3 \%$ & $15.4 \%$ & $15.4 \%$ & $15.4 \%$ & $15.4 \%$ & $11.5 \%$ \\
\hline & SLL2 & $16.7 \%$ & $16.7 \%$ & $15.7 \%$ & $17.6 \%$ & $15.7 \%$ & $13.1 \%$ & $13.1 \%$ & $11.2 \%$ & $12.1 \%$ & $12.1 \%$ & $11.2 \%$ \\
\hline & $\mathrm{CC}$ & $76.3 \%$ & $74.4 \%$ & $72.5 \%$ & $70.0 \%$ & $78.1 \%$ & $85.5 \%$ & $86.2 \%$ & $87.4 \%$ & $86.8 \%$ & $86.8 \%$ & $88.7 \%$ \\
\hline & WE & $30.0 \%$ & $25.6 \%$ & $20.7 \%$ & $17.0 \%$ & $34.1 \%$ & $53.4 \%$ & $55.3 \%$ & $58.1 \%$ & $56.7 \%$ & $56.7 \%$ & $62.2 \%$ \\
\hline \multirow{8}{*}{$\begin{array}{c}3 \\
\text { năm }\end{array}$} & SLL1 & $78.0 \%$ & $80.0 \%$ & & & $78.0 \%$ & $42.0 \%$ & $42.0 \%$ & $42.0 \%$ & & & $42.0 \%$ \\
\hline & SLL2 & $7.5 \%$ & $4.7 \%$ & & & $7.5 \%$ & $10.5 \%$ & $11.4 \%$ & $9.5 \%$ & & & $12.4 \%$ \\
\hline & CC & $70.1 \%$ & $71.3 \%$ & & & $70.1 \%$ & $79.4 \%$ & $78.7 \%$ & $80.0 \%$ & & & $78.1 \%$ \\
\hline & WE & $8.9 \%$ & $9.5 \%$ & & & $8.9 \%$ & $33.4 \%$ & $32.3 \%$ & $34.5 \%$ & & & $31.3 \%$ \\
\hline & SLL1 & $44.0 \%$ & $48.0 \%$ & & & $44.0 \%$ & $20.0 \%$ & $20.0 \%$ & $20.0 \%$ & & & $20.0 \%$ \\
\hline & SLL2 & $18.7 \%$ & $21.5 \%$ & & & $17.8 \%$ & $22.9 \%$ & $23.8 \%$ & $23.8 \%$ & & & $23.8 \%$ \\
\hline & $\mathrm{CC}$ & $73.2 \%$ & $70.1 \%$ & & & $73.9 \%$ & $78.1 \%$ & $77.4 \%$ & $77.4 \%$ & & & $77.4 \%$ \\
\hline & WE & $23.9 \%$ & $19.3 \%$ & & & $24.6 \%$ & $39.0 \%$ & $38.1 \%$ & $38.1 \%$ & & & $38.1 \%$ \\
\hline
\end{tabular}

Ghi chú: Dòng đầu dùng mốc phân loại 0.5, dòng hai dùng mốc phân loại theo Martin (1977)

Nguồn: Kết quả xử lý dữ liệu của nhóm nghiên cứu

\section{Kết luận}

Trong bài nghiên cứu này, chúng tôi đã kiểm tra ảnh hưởng của tin tức truyền thông đến tình trạng kiệt quệ tài chính. Tin tức từ phương tiện truyền thông được định lượng hóa và xây dựng thành 4 biến khác nhau, 4 biến này được đưa vào mô hình hồi quy logistic một cách riêng lẻ lẫn kết hợp với nhóm biến định lượng để so sánh khả năng dự báo và giải thích tình trạng kiệt quệ tài chính của từng biến thuộc nhóm DIDC từ đó xem xét cụ thể cách mà tin tức truyền thông tác động đến tình trạng kiệt quệ tài chính. Bài nghiên cứu đã chỉ ra rằng các biến thuộc nhóm DIDC có ảnh hưởng cùng chiều đến tình trạng kiệt quệ tài chính, trong đó biến DIDC thuần là biến có ảnh hưởng mạnh mẽ nhất và có hiệu ứng dẫn dắt đối với nhóm biến tin tức truyền thông. Một kết quả khác đó là khi đưa các biến DIDC vào mô hình dự báo kiệt quệ, độ chính xác của mô hình đã tăng lên, điều này chứng minh tin tức truyền thông không chỉ có khả năng giải thích tình hình kiệt quệ tài chính mà còn có thể đưa vào mô hình dự báo kiệt quệ để giúp mô hình trở nên tối ưu hơn. 


\section{Tài liệu tham khảo}

Altman, E. I. (1968). Financial ratios, discriminant analysis and the prediction of corporate bankruptcy. The Journal of Finance, 23(4), 589-609.

Altman, E. I. (2000). Predicting financial distress of companies: Revisiting the Z-score and ZETA models. Retrieved May 11, 2017, from https://www.semanticscholar.org/paper/Predicting-FinancialDistress-of-Companies\%3A-the-and-Altman/b6258e30c9f71c48e803929562b18c1185956f9d

Beaver, W. H. (1966). Financial ratios as predictors of failure. Journal of Accounting Research, 4, 71-111.

Bhimani, A., Gulamhussen, M. A., \& Lopes, S. D.-R. (2010). Accounting and non-accounting determinants of default: An analysis of privately-held firms. Journal of Accounting and Public Policy, 29(6), 517-532.

Cao, Z., Leng, F., Feroz, E. H., \& Davalos, S. V. (2015). Corporate governance and default risk of firms cited in the SEC's accounting and auditing enforcement releases. Review of Quantitative Finance and Accounting, 44(1), 113-138.

Demers, E. A., \& Vega, C. (2014). Understanding the role of managerial optimism and uncertainty in the price formation process: Evidence from the textual content of earnings announcements. $\quad$ Retrieved May 12, 2017, from https://www.semanticscholar.org/paper/Understanding-The-Role-of-ManagerialOptimism-and-Demers-Vega/a258e3d6c5a4b5869e8399fa044682ac9862b64b

Engelberg, J. E., \& Parsons, C. A. (2011). The causal impact of media in financial markets. The Journal of Finance, 66(1), 67-97.

Figlewski, S., Frydman, H., \& Liang, W. (2006). Modeling the effect of macroeconomic factors on corporate default and credit rating transitions. International Review of Economics \& Finance, 21(1), 87-105.

Johnson, S., Boone, P., Breach, A., \& Friedman, E. (2000). Corporate governance in the Asian financial crisis. Journal of financial Economics, 58(1), 141-186.

Korobow, L., \& Stuhr, D. (1985). Performance measurement of early warning models: Comments on West and other weakness/failure prediction models. Journal of Banking \& Finance, 9(2), 267-273.

Lee, T. S., \& Yeh, Y. H. (2004). Corporate governance and financial distress: Evidence from Taiwan. Corporate governance: An international review, 12(3), 378-388.

Lu, Y.-C., Wei, Y.-C., \& Chang, T.-Y. (2015). The effects and applicability of financial media reports on corporate default ratings. International Review of Economics \& Finance, 36, 69-87.

Martin, D. (1977). Early warning of bank failure: A logit regression approach. Journal of Banking \& Finance, 1(3), 249-276.

Nguyen, T. T. H., \& Nguyen, M. T. N. (2014). Sự truyền tải thông điệp của dữ liệu phi cấu trúc trong dự báo kiệt quệ tài chính của các doanh nghiệp Việt Nam [The transmission of the 
message of unstructured data in forecasting financial exhaustion of Vietnamese businesses]. Tạp chí Phát triển và hội nhập, 19(29), 19-27.

Prowse, S. (1998). Corporate governance: Emerging issues and lessons from east asia, responding to global financial crisis. Washington, DC: The World Bank.

Rajan, R., \& Zingales, L. (1998). Which capitalism? Lessons from the East Asia crisis. Journal of Applied Corporate Finance, 11(3), 40-48.

Shumway, T. (2001). Forecasting bankruptcy more accurately: A simple hazard model. The Journal of Business, 74(1), 101-124.

Tetlock, P. C. (2007). Giving content to investor sentiment: The role of media in the stock market. The Journal of Finance, 62(3), 1139-1168.

Tetlock, P. C., Saar-Tsechansky, M., \& Macskassy, S. (2008). More than words: Quantifying language to measure firms' fundamentals. The Journal of Finance, 63(3), 1437-1467.

Tinoco, M. H., \& Wilson, N. (2013). Financial distress and bankruptcy prediction among listed companies using accounting, market and macroeconomic variables. International Review of Financial Analysis, 30, 394-419.

Yang, Y., \& Pedersen, J. O. (1997). A comparative study on feature selection in text categorization. $\quad$ Retrieved May 12, 2017, from http://www.surdeanu.info/mihai/teaching/ista555spring15/readings/yang97comparative.pdf 